\title{
Remote Sensing Image Classification of the Improved BP NN
}

\author{
Xiangwei Liu \\ Foundation Department, PLA University of Foreign Languages, Luoyang 471003, China \\ E-mail: liuxwletter@163.com
}

\begin{abstract}
Remote sensing (RS) image classification plays the very important practical role in the geological survey and mineral exploration. The neural network (NN) technology is an important method for the RS image classification. But, the BP NN still has shortcomings, for example, the learning convergence rate is slow and the training process is easy to fall into the partial minimum. By taking the classification of $512 \times 512$ pixel experimental area of Mulei County of Xinjiang as the example, the improved BP NN model is designed in this article by the adaptive learning rate and the additional momentum, using the LANDSAT-7 ETM + RS images as the main data source. Through the precision analysis by the error matrix, the result shows that the total classification NNaccuracy which uses improved BP NN classification of RS image is $89.06 \%$, and the Kappa coefficient is $85.53 \%$, and the classification accuracy of RS image is improved obviously.
\end{abstract}

Keywords: RS image classification, Improved BP NN, MATLAB, Precision analysis

\section{Introduction}

In the RS geological exploration, the research and application of new technology and method is very important and practical. In the west China, the degree of geological work is deficient, and the mineral exploration is difficult, and the geological exploration cost and risk are increasing continually, so the geological exploration enterprises hope that the quick developing RS technology could provide more and more exact mineral information to enhance the work efficiency and reduce the geological exploration risk (A. W. Siegrist, 1982, P.102-133). Based on the LANDSAT-7 ETM + RS images, taking the experiment regions of Mulei County of Xinjiang with $512 \times 512$ pixel experimental as the research object, by virtue of the ERDAS Imagine 9.1 RS image processing software and the MATLAB NN toolbox, the improved BP NN model is designed to enhance the RS image classification precision, and the method and efficiency of the regional geological survey work, and solve the problem of "same objects with different spectrums" and "different spectrums with same objects" at the same time.

\section{BP learning algorithm}

\subsection{Basic ideas of the BP learning algorithm}

The error back propagation NN is the BP NN, and it is the most usual NN in the mode classification (Gao, 2005, P.45-55). From structure, it is a layered network, with the input layer, the middle layer (the concealed layer), and the output layer. A BP NN may have two or above two middle layers, and the BP NN with only one middle layer is the basic BP NN model.

\subsection{Various improvement of the BP algorithm}

(1) Algorithm of variable step (Wang, 2002, P.45-55)

BP algorithm is based on the gradient method, and in the common optimal gradient methods, the step length $\eta$ is solved by the one-dimensional searching.

(2) Adding the momentum item (Wang, 2002, P.45-55)

To quicken the convergence and prevent the vibration, one momentum factor $\alpha$ is introduced.

$$
w\left(n_{0}+1\right)=w\left(n_{0}\right)+\eta\left(n_{0}\right) d\left(n_{0}\right)+\alpha \Delta w\left(n_{0}\right)
$$

Where, $\alpha$ is the momentum item, and it is usually positive.

The third item is the modification of the weight at the last time, and the modification direction at the time of $\left(n_{0}\right)$ is the combination of the direction at the time of $\left(n_{0}-1\right)$ and the direction at the time of $\left(n_{0}\right)$.

\section{Designing and realizing the improved BP NN model by the MATLAB NN toolbox}

\subsection{The improved BP NN model and initialization}

The RS classification generally adopts a three-layer BP network, and the input node amount equals to the amount of the character of RS image, and the output node amount equals to the classification sorts, and the node of the concealed layer would be confirmed according to the complexity of the problem. In this article, one input node represents one pixel element value of one wave band, and one output node represents one sort of geological object.

The data of the training samples and the testing classification effect are all from the experiment region of Mulei County of Xinjiang with $512 \times 512$ pixel elements, including the LANDSAT-7 images in four wave bands of 2, 3, 5 , and 6 , and the intention of classification is to distinguish the geological object 1 , the geological object 2 , the 
geological object 3 , the geological object 4 , and the geological object 5 . Two groups of data are selected and seen in Table 1, and all data are pretreated before they are input into the network, and the data are limited in $[0,1]$, and the expectation output of samples are defined and seen in Table 2.

The order is “net = newff(minmax(P),[24,5], \{'tansig','logsig'\},'traingdx','learngdm','mse')";

This order establishes the network object and initializes the network weight and deflection, and its input is matrix of $4 \times 300$, and the nerve cell number on the input layer is 4 , and the nerve cell number on the output layer is 5 , and the node amount in the concealed layer is 24 . And the transfer function of the first layer is "tansig", the transfer function of the output layer is "logsig", and the training function is "traingdx".

3.2 MATLAB language realization of the improved BP NN

The improved BP NN model is triggered by the training function "traingdx". The program codes are

$\% \mathrm{~T}$ is the expected output data

net.trainParam.show $=100$;

net.TrainParam.epochs $=10000$;

net. TrainParam.goal $=0.01$;

net.TrainParam.mc $=0.001$;

$\%$ refurbishing the training figure after 100 times training

$\%$ training times

$\%$ target presenting the end of training

$\%$ momentum factor

net.TrainParam. $1 \mathrm{r}=0.9$;

net.TrainParam.lr_inc $=1.0$;

$\%$ basic value of learning speed

$\%$ increasing rate of learning speed

net.TrainParam.lr_dec $=0.05$;

$\%$ decreasing rate of learning speed

$\%$ The error square performance curve of the improved BP NN is seen in Figure 1, and the error square performance curve of the traditional BP NN is seen in Figure 2.

net $=\operatorname{train}($ net,P,T)

After the codes run, the training state of the network will be displayed real time as follows.

TRAINGDX, Epoch 0/2000, MSE 0.441636/0.01, Gradient $0.106047 / 1 \mathrm{e}-006$

TRAINGDY, Epoch 100/2000, MSE 0.0564091/0.01, Gradient 0. 0258736/1e-006

TRAINGDY, Epoch 200/2000, MSE 0.0273646/0.01, Gradient $0.0124348 / 1 \mathrm{e}-006$

TRAINGDY, Epoch 300/2000, MSE 0.0182401/0.01, Gradient 0.00813699/1e-006

TRAINGDY, Epoch 400/2000, MSE 0.0137801/0.01, Gradient 0. 00609211/1e-006

TRAINGDX, Epoch 500/2000, MSE 0.0110986/0.01, Gradient 0. 00488183/1e-006

TRAINGDX, Epoch 558/2000, MSE 0.00998592/0.01, Gradient 0. 00435737/1e-006

TRAINGDX, Performance goal met.

$\mathrm{Y}=\operatorname{sim}($ net,P) $\quad \%$ simulated training data

error $=\mathrm{Y}-\mathrm{T} ; \quad \%$ testing the errors of the simulation data

res $=$ norm(error)

\subsection{Comparison of running results}

For the comparison, the same network structure is adopted in the improved BP algorithm and the traditional BP algorithm, and when the iteration times exceeds the appointed 10000 times, the training ends. Table 3 lists the result comparison of two methods.

From Table 3, it is obvious that it is feasible that to adopt the improved BP NN to classify the RS images on the platform of the MATLAB NN toolbox.

\subsection{To classify the experiment area by the improved BP model}

Through the testing of the data, both the improved BP NN and the traditional NN accord with the requirements, and achieve the stable state, and then the program reads the data of the whole image, and classify it.

$\mathrm{I}=$ imread ('study the region image file') \% read the image in the research region

$\%$ load the data in the wave bands of 2, 3, 5, 6 as the input data

$\%$ standardize the data in the wave bands of $2,3,5,6$

$\%$ simulate the data in the research region

$\mathrm{Y}=\operatorname{sim}($ net, $\mathrm{P})$

$\%$ take out the data on rows and translate them into the data in the matrix of $512 \times 512$

$\%$ respectively translate the data on rows into the grey image, and the saving format is .tif

Through above programs, the simulation result could be obtained, and the result is translated into the classification image (seen in Figure 3). 
The classification image obtained from the traditional BP NN algorithm based on the MATLAB NN toolbox is seen in Figure 4.

\section{Analysis of classification result}

\subsection{Evaluation index of classification precision}

The precision evaluation is to compare the variance among each pixel element in two images. In most instances, it is hard to obtain an exact reference image, so most precision evaluation is to evaluate one part of pixel elements in the image sampling. The error matrix (i.e. the confusion matrix) is usually used to denote the precision of the classification result in the RS image classification, and based on that, various statistics could be computed and the statistical test could be implemented, and the classification precisions based the total and various ground types could be obtained finally.

\subsection{Analysis of classification result precision}

The ERDAS IMAGINE 9.1 RS image processing software is used in this article to evaluate the precision. The precision evaluation error matrix should be established first, and the error matrix (Dang, 2003, P.1-6) should be generated according to the images in the whole research region, because the size of the research region is $512 \times$ 512 , so the total pixel element amount is 262114 , and according to the real interest regions of the ground, the precisions of the improved BP NN classification and the traditional BP NN classification are respectively evaluated, and the precision evaluation report of the RS image classification figure is seen in Table 4 and Table 5. And the comparison of the pixel element of five geological objects in two classifications is seen in Figure 5.

\section{Conclusions}

The experiment result shows that the total precision of the improved BP NN classification method is $89.06 \%$, with an increase of $8.35 \%$ than the traditional BP NN classification method. For the learning speed, the trained improved BP NN is enhanced largely than the traditional BP NN, with better error tolerance and stability, which could further enhance the ability of the BP NN to dispose the nonlinear and uncertain factors. This advantage could be utilized to provide more and more accurate RS mineral exploration information, enhance the work efficiency, and reduce the geological exploration risk in the geological survey, and it could be also extended in the geological environment evaluation, the geological disaster monitoring, and the natural resource survey.

\section{References}

A. W. Siegrist \& C. C. Schnetyler, interpreted by Wang, Zongliang. (1982). Remote Sensing Special (2): Image Processing and Geological Application. Beijing: Geological Publishing House. P.102-133.

Dang, Anrong, Wang, Xiaodong \& Chen, Xiaofeng. (2003). ERDAS Imagine Remote Sensing Image Processing Method. Beijing: Tsinghua University Press. April, 2003, P.1-6.

Gao, Jun. (2005). Principal and Simulation Examples of ANN. Beijing: Mechanic Industry Press. Aug, 2005, P.45-55.

Wang, Hongyuan \& Shi, Guodong. (2002). ANN Technology and Application. Beijing: China Petrochemical Press. Jan, 2002, P.45-55.

Table 1. Sample data

\begin{tabular}{|c|c|c|}
\hline Sort & Training sample & Training sample \\
\hline Geological object 1 & 50 & 22 \\
\hline Geological object 2 & 66 & 18 \\
\hline Geological object 3 & 75 & 27 \\
\hline Geological object 4 & 45 & 35 \\
\hline Geological object 5 & 64 & 30 \\
\hline
\end{tabular}

Table 2. Expectation output of training samples

\begin{tabular}{|c|c|c|c|c|c|}
\hline Output & 1 & 2 & 3 & 4 & 5 \\
\hline Geological object 1 & 1 & 0 & 0 & 0 & 0 \\
\hline Geological object 2 & 0 & 1 & 0 & 0 & 0 \\
\hline Geological object 3 & 0 & 0 & 1 & 0 & 0 \\
\hline Geological object 4 & 0 & 0 & 0 & 1 & 0 \\
\hline Geological object 5 & 0 & 0 & 0 & 0 & 1 \\
\hline
\end{tabular}


Table 3. Experiment result

\begin{tabular}{|c|c|c|c|c|c|c|}
\hline \multirow{2}{*}{ Method } & \multicolumn{3}{|c|}{ Training data } & \multicolumn{3}{c|}{ Testing data } \\
\cline { 2 - 7 } & $\begin{array}{c}\text { Iteration } \\
\text { times }\end{array}$ & $\begin{array}{c}\text { Training } \\
\text { time/s }\end{array}$ & $\begin{array}{c}\text { Error square } \\
\text { sum }\end{array}$ & $\begin{array}{c}\text { Iteration } \\
\text { times }\end{array}$ & $\begin{array}{c}\text { Training } \\
\text { time/s }\end{array}$ & $\begin{array}{c}\text { Error square } \\
\text { sum }\end{array}$ \\
\hline Improved BP algorithm & 558 & 53.23 & 0.690 & 219 & 12.68 & 0.732 \\
\hline Traditional BP algorithm & 3089 & 289.65 & 1.343 & 2354 & 176 & 1.128 \\
\hline
\end{tabular}

Table 4. Improved BP NN

\begin{tabular}{|c|c|c|c|c|c|c|c|c|}
\hline \multirow{2}{*}{\multicolumn{2}{|c|}{$\begin{array}{c}\text { Classification } \\
\text { data }\end{array}$}} & \multicolumn{5}{|c|}{ Reference data } & \multirow{2}{*}{$\begin{array}{l}\text { Sum of row } \\
\text { numbers }\end{array}$} & \multirow{2}{*}{ User precision } \\
\hline & & $\begin{array}{c}\text { Geological } \\
\text { object } 1\end{array}$ & $\begin{array}{c}\text { Geological } \\
\text { object } 1\end{array}$ & $\begin{array}{c}\text { Geological } \\
\text { object } 1\end{array}$ & $\begin{array}{c}\text { Geological } \\
\text { object } 1\end{array}$ & $\begin{array}{c}\text { Geological } \\
\text { object } 1\end{array}$ & & \\
\hline \multirow{5}{*}{ 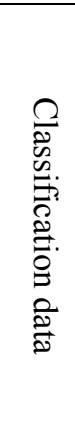 } & $\begin{array}{l}\text { Geologica } \\
1 \text { object } 1\end{array}$ & 78640 & 1553 & 1218 & 211 & 665 & 82287 & $95.57 \%$ \\
\hline & $\begin{array}{l}\text { Geologica } \\
1 \text { object } 2\end{array}$ & 3266 & 45813 & 2107 & 305 & 258 & 51749 & $88.53 \%$ \\
\hline & $\begin{array}{l}\text { Geologica } \\
1 \text { object } 3\end{array}$ & 3536 & 3245 & 61125 & 774 & 1986 & 70666 & $86.50 \%$ \\
\hline & \begin{tabular}{|l|} 
Geologica \\
1 object 4
\end{tabular} & 153 & 168 & 126 & 10406 & 2154 & 13007 & $80.00 \%$ \\
\hline & $\begin{array}{l}\text { Geologica } \\
1 \text { object } 5\end{array}$ & 4279 & 295 & 1292 & 1089 & 37480 & 44435 & $84.35 \%$ \\
\hline \multicolumn{2}{|c|}{$\begin{array}{l}\text { Sum of column } \\
\text { numbers }\end{array}$} & 89874 & 51074 & 65868 & 12785 & 42543 & 262144 & \\
\hline \multicolumn{2}{|c|}{$\begin{array}{l}\text { Production } \\
\text { precision }\end{array}$} & $87.50 \%$ & $89.70 \%$ & $92.80 \%$ & $81.40 \%$ & $88.10 \%$ & \multicolumn{2}{|c|}{ Khat $=85.53 \%$} \\
\hline \multicolumn{9}{|c|}{ Total precision $=(78640+45813+61125+10406+37480) / 262144=89.06 \%$} \\
\hline
\end{tabular}

Table 5. Traditional BP NN

\begin{tabular}{|c|c|c|c|c|c|c|c|c|}
\hline \multirow{2}{*}{\multicolumn{2}{|c|}{$\begin{array}{c}\text { Classification } \\
\text { data }\end{array}$}} & \multicolumn{5}{|c|}{ Reference data } & \multirow{2}{*}{$\begin{array}{l}\text { Sum of row } \\
\text { numbers }\end{array}$} & \multirow{2}{*}{ User precision } \\
\hline & & \begin{tabular}{|c|} 
Geological \\
object 1
\end{tabular} & \begin{tabular}{|c|} 
Geological \\
object 1
\end{tabular} & $\begin{array}{c}\text { Geological } \\
\text { object } 1\end{array}$ & $\begin{array}{c}\text { Geological } \\
\text { object } 1\end{array}$ & $\begin{array}{c}\text { Geological } \\
\text { object } 1\end{array}$ & & \\
\hline \multirow{5}{*}{ 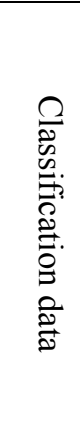 } & $\begin{array}{l}\text { Geologica } \\
1 \text { object } 1\end{array}$ & 71252 & 1973 & 2518 & 185 & 3042 & 78970 & $90.23 \%$ \\
\hline & \begin{tabular}{|l|} 
Geologica \\
1 object 2
\end{tabular} & 10154 & 44685 & 4017 & 141 & 213 & 59210 & $75.47 \%$ \\
\hline & \begin{tabular}{|l|} 
Geologica \\
1 object 3
\end{tabular} & 2435 & 4025 & 49829 & 629 & 1899 & 58817 & $84.72 \%$ \\
\hline & $\begin{array}{l}\text { Geologica } \\
1 \text { object } 4\end{array}$ & 241 & 122 & 1008 & 8967 & 3159 & 13497 & $66.44 \%$ \\
\hline & $\begin{array}{l}\text { Geologica } \\
1 \text { object } 5\end{array}$ & 5792 & 269 & 8496 & 2863 & 34230 & 51650 & $66.27 \%$ \\
\hline \multicolumn{2}{|c|}{$\begin{array}{l}\text { Sum of column } \\
\text { numbers }\end{array}$} & & 51074 & 65868 & 12785 & 42543 & 262144 & \\
\hline \multicolumn{2}{|c|}{$\begin{array}{l}\text { Production } \\
\text { precision }\end{array}$} & & $87.49 \%$ & $75.65 \%$ & $70.14 \%$ & $80.46 \%$ & \multicolumn{2}{|c|}{ Khat $=76.05 \%$} \\
\hline \multicolumn{9}{|c|}{ Total precision $=(71252+44685+49829+8967+34230) / 262144=79.71 \%$} \\
\hline
\end{tabular}




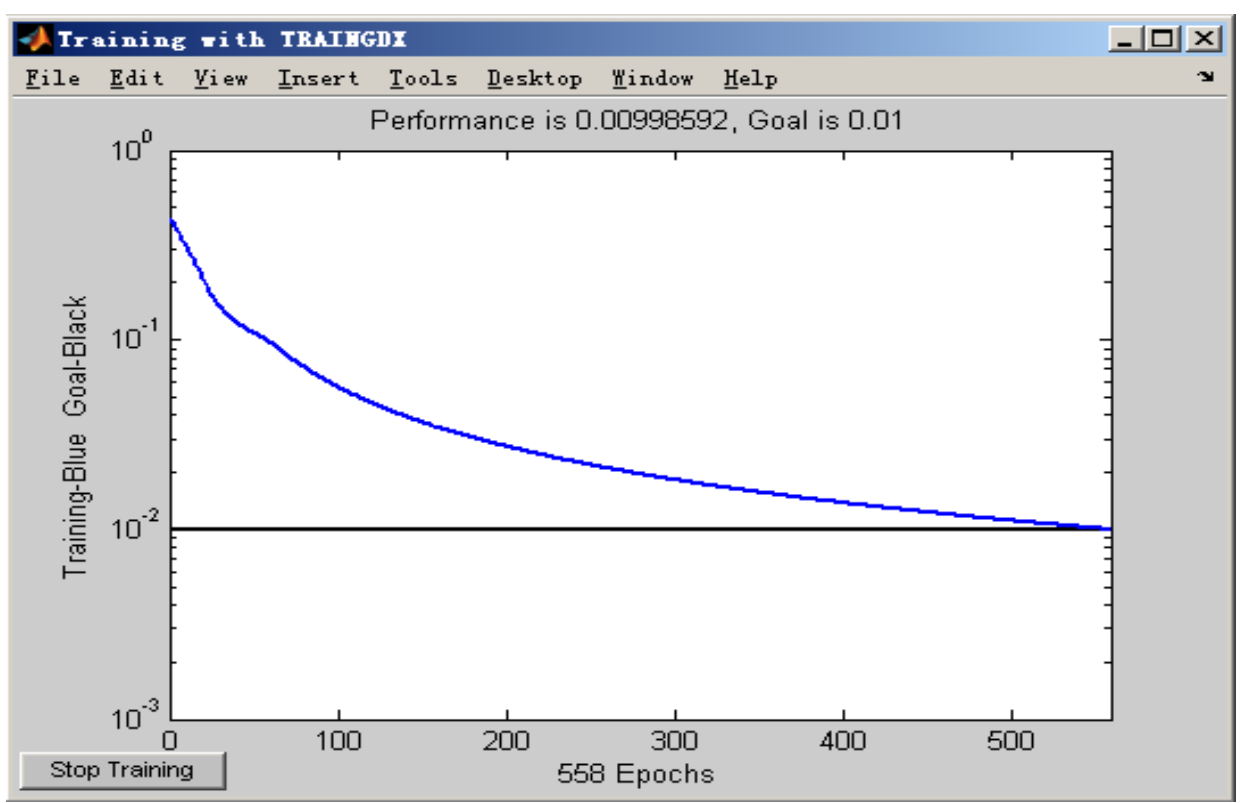

Figure 1. Improved BP NN Error Curve

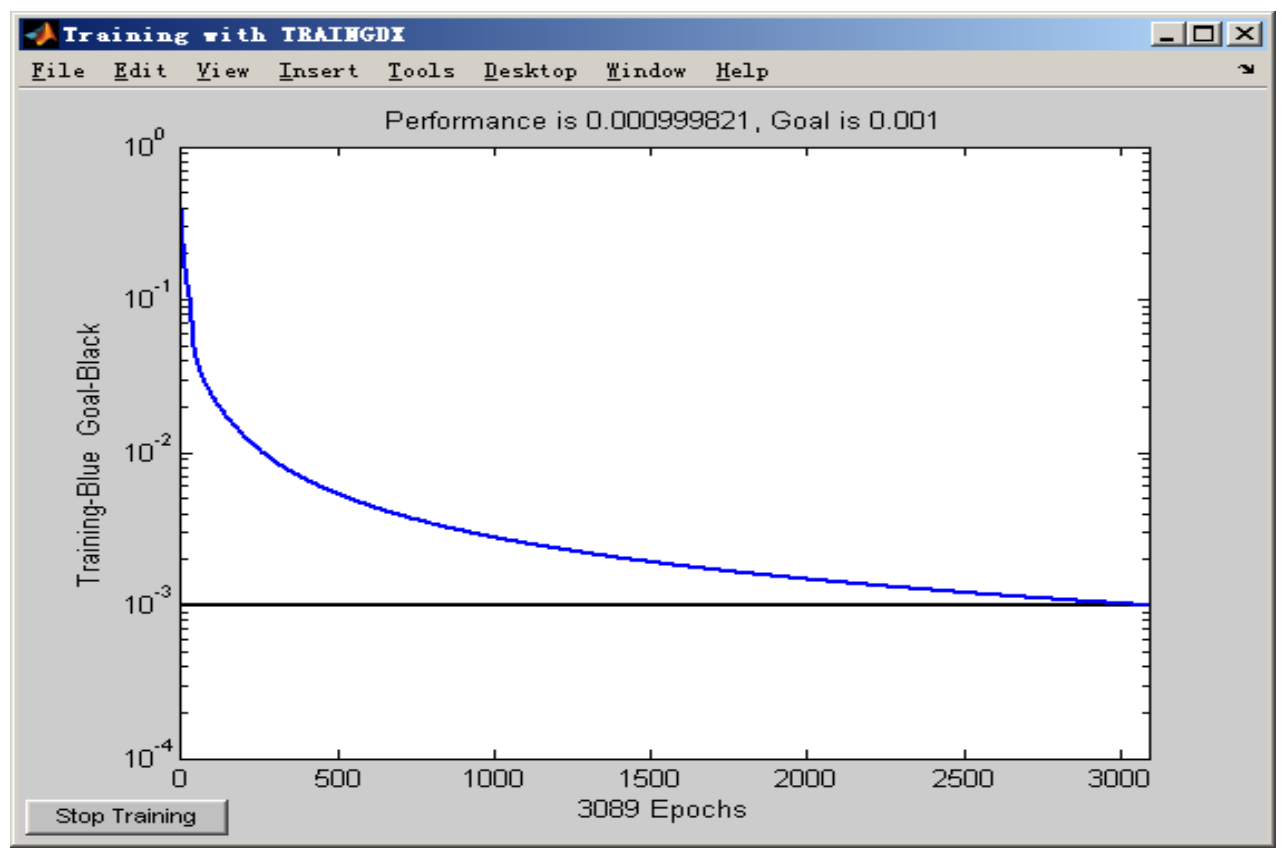

Figure 2. Traditional BP NN Error Curve 

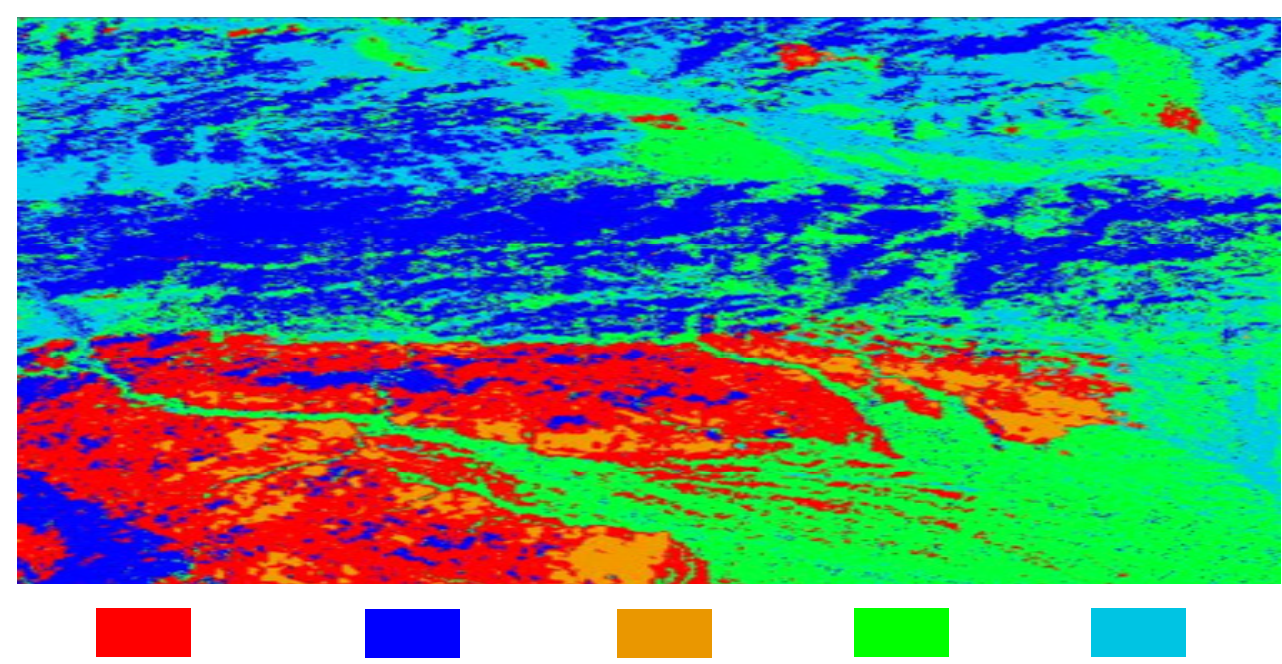

Geological object 1 Geological object 2 Geological object3 Geological object 4 Geological object 5

Figure 3. Remote Sensing Image Classification Based on the Improved BP NN

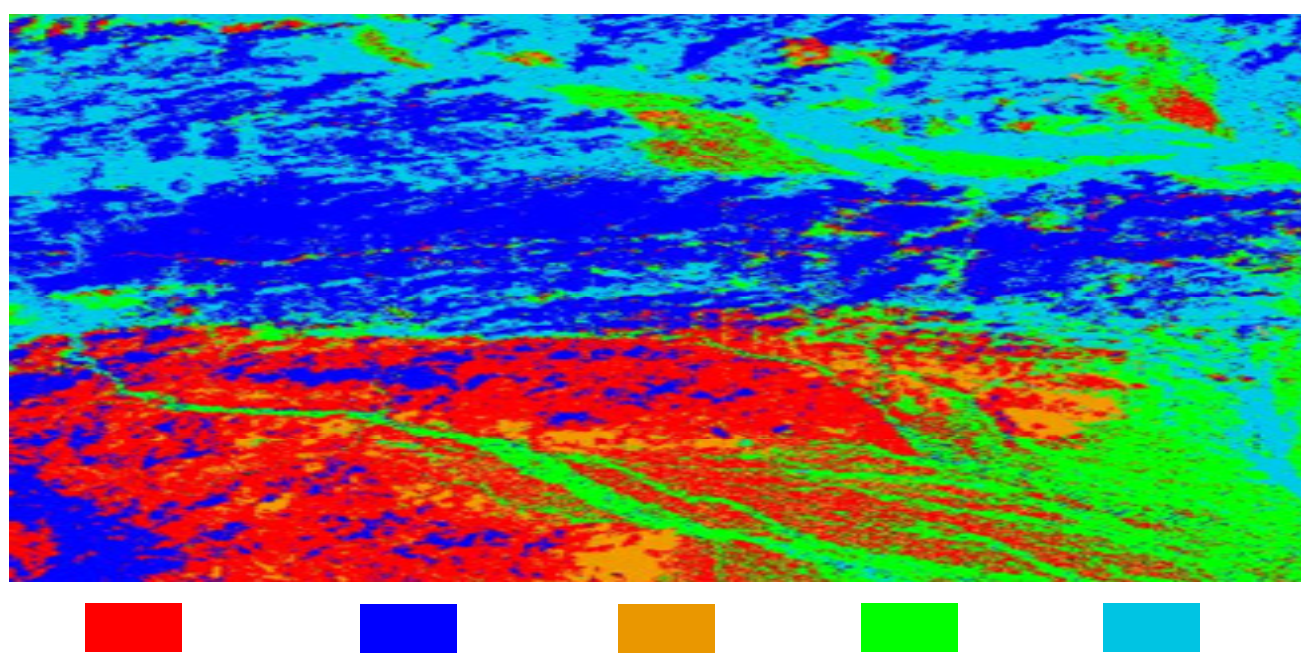

Geological object 1 Geological object2 Geological object3 Geological object 4 Geological object 5

Figure 4. Remote Sensing Image Classification Based on the Traditional BP NN

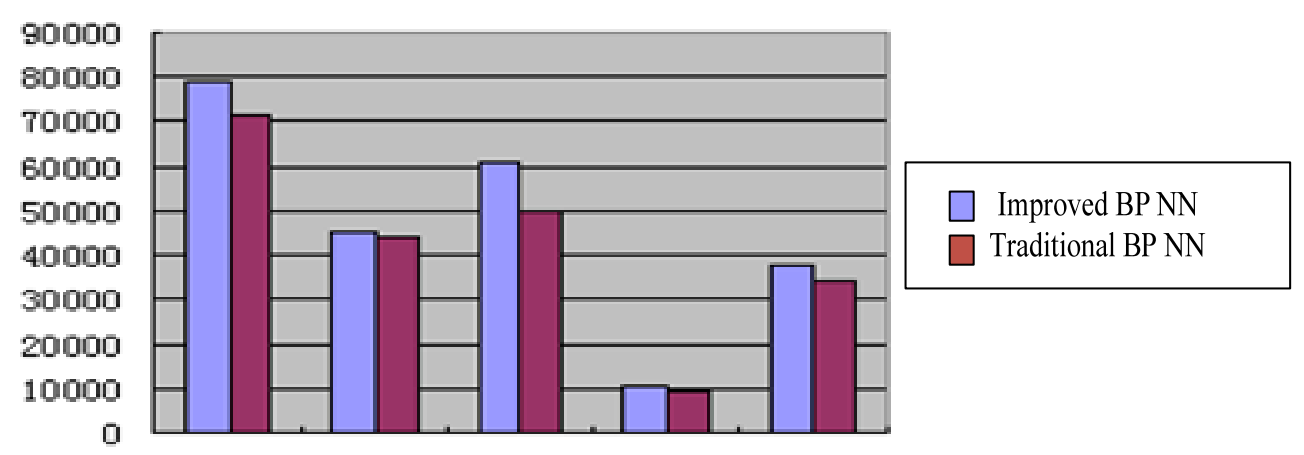

Geological object 1 Geological object 2 Geological object 3 Geological object 4 Geological object 5

Figure 5. Image Element Amounts of Five Geological Objects in Different Classification Methods 